\title{
Congenital defect of the pericardium
}

\author{
E. G. H. BRUNING \\ From the South African Institute for Medical Research, Department of \\ Histopathology (Bloemfontein Branch)
}

SYNOPSIS The morbid anatomy and histopathology is described as found at necropsy on a 7-yearold coloured girl who suffered from partial defect of the pericardium with prolapse and partial incarceration of the cardiac apex. Because of the absence of any history of illness during life the defect is considered to have been congenital, and because of the lack of any other significant necropsy findings, it is considered to have been the cause of death.

There is no doubt that progress in radiography, thoracoscopy, and thoracic surgery has increased our knowledge and stimulated the writing of case reports of partial pericardial defects or even of complete absence of the pericardial sac. We thus know that the condition is not necessarily fatal (Fry, 1953; Hering, Wilson, and Ball, 1960; Ronka and Tessmer, 1944; Rusby and Sillors, 1945; Shafiroff, 1951). Nevertheless, case reports are extremely rare, so that the following detailed anatomical and histological description of a case is justified, especially as the defect was responsible for the sudden death of the patient.

\section{CASE REPORT}

The report concerns a poorly nourished and small 7-yearold coloured girl, who suffered from a short coughing attack, became immediately unconscious and died 15 minutes after being admitted to hospital. Her left hand lay on the heart region, probably indicating a terminal precordial pain. The cause of death was not apparent.

External examination showed a gracile, slender, but well-built coloured girl of about 7 years.

Elevation of the sternum showed emphysematous lungs with rounded margins which completely covered the heart. On the left side there were several cord-like pleural adhesions, which were easily detached manually. Removal of the left lung revealed a purplish, button-like tumour, corresponding to the apex of the heart, with white icing sugar-like (Zuckerguss) plaques and varicose, extremely congested tortuous vessels on the surface. Careful exploration showed a partial defect of the pericardium, $2.7 \mathrm{~cm}$. in diameter and nearly $8 \mathrm{~cm}$. in circumference, through which the apex of the heart had prolapsed and in which the prolapse had been incarcerated (Figs. 1-4). The greatest circumference of the incarcerated part measured $9 \mathrm{~cm}$., so that there was a well-marked 'laced

Received for publication 9 October 1961. waist' separating the whole of the cardiac apex after cutting open the buttonhole-like pericardial ring.

After prolonged formol fixation of the specimen the following findings were noted:-

The whole heart, including the apex, was very muscular and fully contracted. The muscular wall of the left ventricle measured $1 \mathrm{~cm}$., the right $0.6 \mathrm{~cm}$. The apex of the left ventricle was within the incarcerated part and filled with clotted blood (washed away in Fig. 5). Here the endocardium was locally thickened and whitish. The myocardium was purplish and showed yellowish spots throughout, with marked patchy perivascular and interstitial fibrosis. The epicardial layer of the apex and of the posterior surface of the heart was focally thickened and white. The superficial veins of the heart apex were extremely congested. The descending branches of the right coronary artery supplying the cardiac apex showed a wide lumen and a marked thickening of the wall, even at the periphery (see Fig. 5). The foramen ovale was obliquely patent.

Further dissection showed macroscopically several cord-like pleural adhesions on both sides, two calcified lymph nodes at the left lung hilus, an acute vesicular emphysema, mucinous tracheobronchitis, and evidence of acute venous congestion of all the internal organs with marked fatty changes of liver and with congestion of the mucous membranes and of the brain.

\section{HISTOLOGY}

Representative histological blocks from the incarcerated apex, stained with haematoxylin and eosin and Masson's trichrome and elastic-van Gieson stains, showed the following changes (Fig. 6):-

The epicardium has plateau-like elevations and is thickened, but without any cellular infiltrate. Veins and arteries are extremely congested with a well-marked oedematous loosening of perivascular tissue. The intimal layers of the peripheral right coronary artery show advanced fibrous thickening. The myocardium of the apex of the heart and the adjacent non-incarcerated 


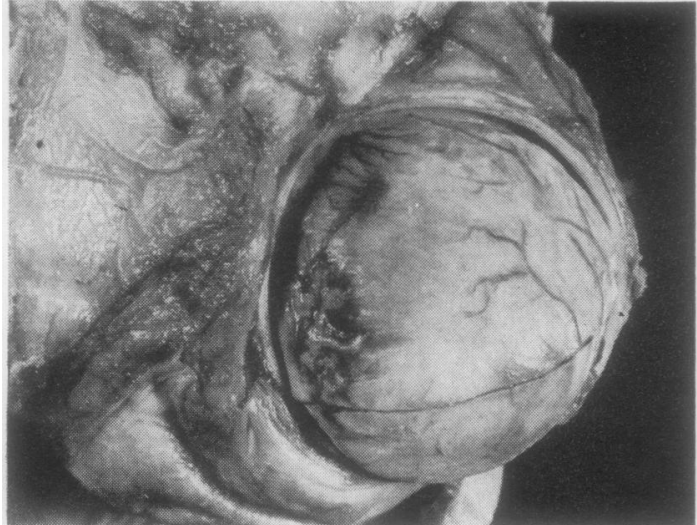

FIG. 1 .

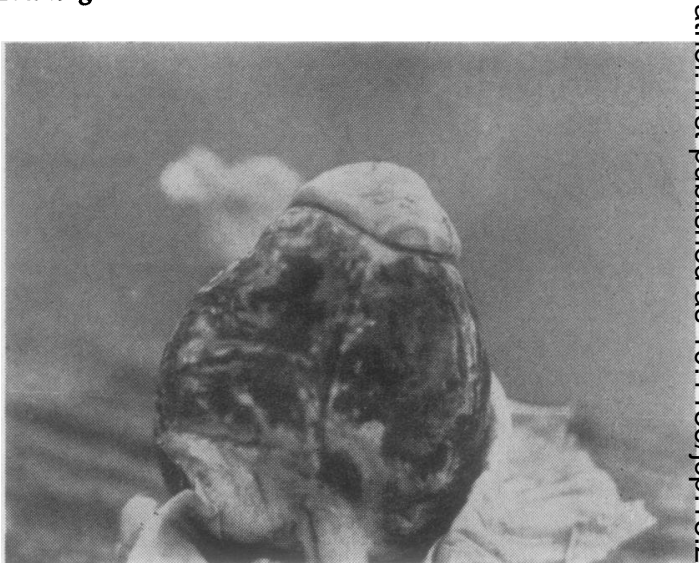

FIG. 2 .

FIG. 1. Left fronto-lateral view of the heart specimen after formol fixation. The buttonhole-like mechanism of the peri cardial ring is cut open and hence the incarcerated heart prolapse becomes more obvious.

FIG. 2. View of the posterior surface of the heart and the incarcerated prolapse of the apex. Note the patchy epi $\vec{z}$ cardial fibrosis (Zuckerguss) and the 'laced waist'. The pericardial sac has been dissected off; the heart stands on its base.

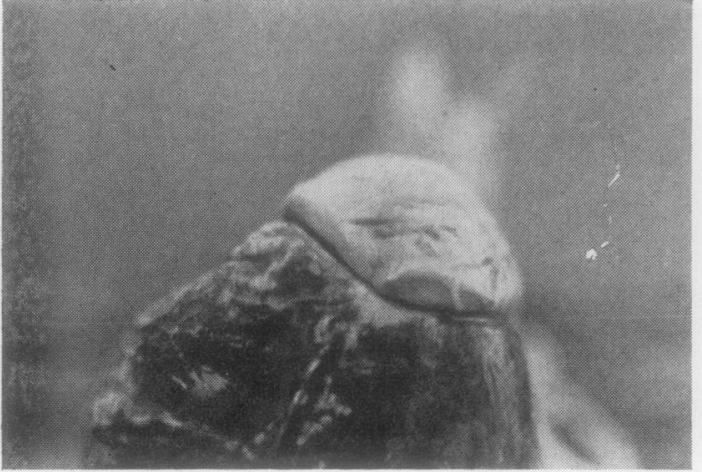

FIG. 3 .

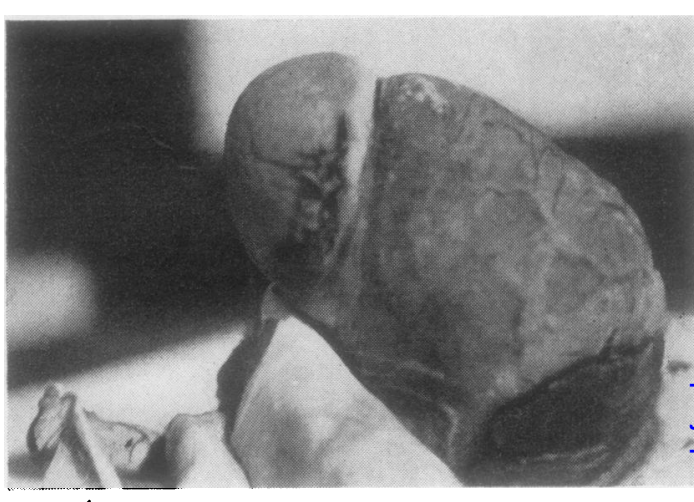

FIG. 4 .

FIG. 3. The 'laced waist' dividing the apex in a higher magnification. Dorsal aspect. Note also the patchy congestion of the myocardium.

FIG. 4. Right lateral view of the dissected heart, which stands on its base.

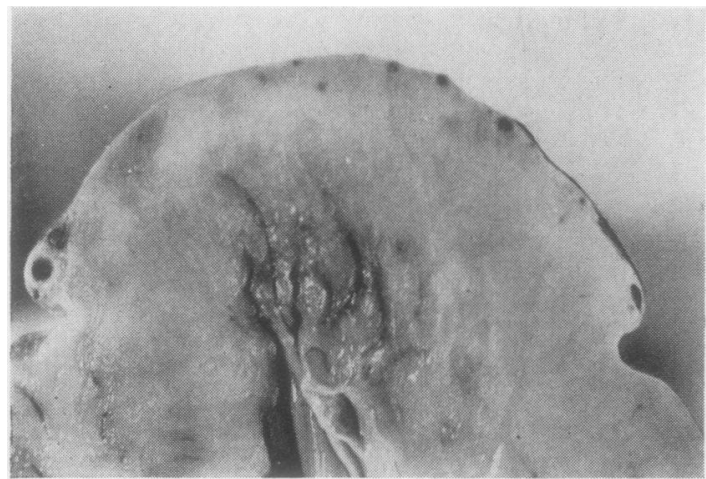

FIG. 5. The cut surface of the incarcerated heart prolapse्t with the apex of the left ventricle in the prolapse. Note the focal circulatory disturbances of the hypertrophied myocardium, the endocardial fibrosis, the ectasia and stiffness of the peripheral part of the descending branch of the righ coronary artery and finally the congested subepicardiat veins.

FIG. 5 . 


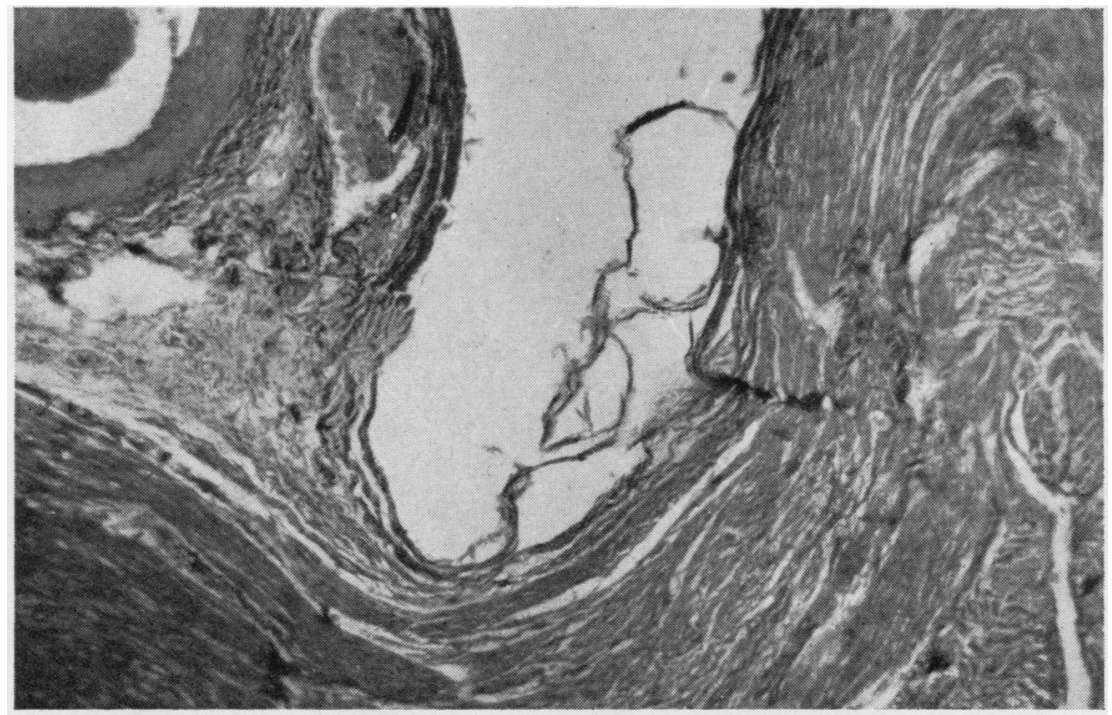

FIG. 6. The vicinity of the 'laced waist' histologically. Congested vessels and subepicardial pools of oedema are visible in the apical incarcerated part (top) and interstitial patchy fibrosis is apparent at the bottom.

parts are loosened by mucoid and oedematous pools. Softening of tissue is most obvious in pre-existing perivascular and interstitial scars. The heart muscle is hypertrophied and in the incarcerated part there are several early necrotic foci. The intramural vessels are also extremely congested. The endocardium at the apex of the left ventricle is markedly fibrosed and thickened. The microscopical examination of the other internal organs failed to reveal any change worth mentioning, except acute venous congestion.

\section{COMMENT}

As far as we have been able to check the world literature this patient is the third in whom death was due to partial defect of the pericardium. In 1938 Southworth and Stevenson collected a list of 54 cases, 45 of which they accepted, excluding all monstrous malformations of the whole body seen in anatomical museums. According to Southworth and Stevenson (1938), most of the defects were on the left side, most of the patients were males, and only three complained of precordial (or thoracic) pain. The ages of the patients ranged from newborn to 75 years. Incarceration was described in three (Cases 11, 21, and 41) but was the direct cause of death in only one patient in whom death occurred three days after confinement and was probably due to acute incarceration following labour. In six cases the defect was associated with other congenital anomalies, Cases 43 and 11 with bipartite heart apex, Case 34 with 'several peritoneal anomalies', Case 23 with agenesis of the left kidney, Case 14 with uncommon lobulation of the lungs, and Case 47 with only two cusps in the aortic valve. Southworth and Stevenson found that $27 \%$ of the patients died from lung diseases, which may extend to the uncovered heart and cause pericarditis.

A second case of fatal incarceration of part of the heart into a pericardial defect is described by Sunderland and Wright-Smith (1944) in a 2-year-old boy, with findings very similar to our own. The theories of the cause of this anomaly are discussed in the literature.

I wish to thank Dr. C. A. Sleggs, Medical Superintendent of the West End Hospital, Kimberley, for permission to publish the case and the Director of the South African Institute for Medical Research for facilities granted.

\section{REFERENCES}

Fry, W. (1953). Amer. J. Surg., 86, 763.

Hering, A. C., Wilson, J. S., and Ball, R. E. (1960). J. thorac. cardiov. Surg., 40, 49.

Ronka, E. K. F., and Tessmer, C. F. (1944). Amer. J. Path., 20, 137 Rusby, N. L., and Sellors, T. H. (1945). Brit. J. Surg., 32, 357.

Shafiroff, B. G. P. (1951). J. thorac. Surg., 21, 30.

Southworth, H., and Stevenson, C. S. (1938). Arch. intern. Med., 61, 223.

Sunderland, S., and Wright-Smith, R. J. (1944). Brit. Heart. J., 6, 167. 